\title{
Erratum
}

\section{In Vitro Pharmacodynamics of CKD-602 in HT-29 Cells}

In-Sook Park, Mee Ryung Ahn, Soo Kyung Suh, Hong-Serck Choi, Soo Jung Sohn, Ji Sun Yang, Tae Moo Yoo ${ }^{2}$, and Hyo-Jeong Kuh ${ }^{1,2}$

Department of Pharmacology, National Institute of Toxicological Research, Korea Food and Drug Administration, 5 Nokbun-Dong, Eunpyung-ku, and ${ }^{1}$ Catholic Research Institutes of Medical Science, The Catholic University of Korea, 505 Banpo-dong, Seocho-ku, Seoul, Korea. ${ }^{2}$ Corresponding authorship is shared by Hyo-Jeong Kuh and Tae Moo Yoo

The correct title is

"Pharmacokinetic-Pharmacodynamic Relationship of a Camptothecin Analogue In Vitro". 